\title{
Demand response program for smart grid through real time pricing and home energy management system
}

\author{
Shibily Joseph ${ }^{1}$, E. A. Jasmin ${ }^{2}$ \\ ${ }^{1}$ Department of Computer Science and Engineering, Govt. Engineering College, Palakkad, India \\ ${ }^{2}$ Department of Electrical Engineering, Govt. Engineering College, Idukki, Kerala State, India
}

\begin{abstract}
Article Info
Article history:

Received Aug 21, 2020

Revised Dec 20, 2020

Accepted Mar 5, 2021

Keywords:

Demand response

Home energy management

Real time pricing

Smart grid

Smart home

ABSTRACT

Aim of demand response (DR) programs are to change the usage pattern of electricity in such a way that, beneficial to the consumers as well as to the distributors by applying some methods or technology. This way additional cost to erect new energy sources can be postponed in power grid. Best method to implement demand response (DR) program is by influencing consumer through the implementation of real time pricing scheme. To harness the benefit of DR, automated home energy management system is essential. This paper presents a comprehensive demand response system with real time pricing. The real time price is determined after considering price elasticity of various classes of consumers and their load profiles. A real time clustering algorithm suitable for big data of smart grid is devised for the segmentation of consumers. This paper is novel in its design for real time pricing and modelling and automatic scheduling of appliances for home energy management. Simulation results showed that this new real time pricing method is suitable for DR programs to reduce the peak load of the system as well as reducing the energy expenditure of houses, while ensuring profit for the retailer.
\end{abstract}

This is an open access article under the CC BY-SA license.

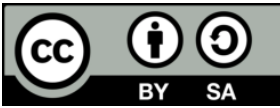

\section{Corresponding Author:}

Shibily Joseph

Department of Computer Science and Engineering

Govt. Engineering College, Palakkad, 678633-India

Email: shibilyj@gecskp.ac.in

\section{INTRODUCTION}

Demand response (DR) programs are playing a pivotal role in balancing the supply and demand of electricity by introducing load flexibility instead of only adjusting generation levels during different time slots of the day [1]. In the DR, homes with energy storage and automated home energy management system (HEMS) can schedule appliances according to variation in prices and contribute to the load reduction. The primary objective of the home energy management system (HEMS) is to minimize the total cost of energy consumption of an entire day, by considering the operating constraints. The success of a home energy management system depends on the effective scheduling of controllable loads [2].

Demand response programs are classified into two categories: incentive-based programs and price based programs [3]. The price based programs give customers time varying rates which reflect the value and cost of electricity in different time periods so that customers tend to consume less electricity during peakprice periods. Typical price based programs include real-time pricing, critical-peak pricing, variable peak pricing and time of use pricing (ToU) [4]. Typical incentive based programs include: direct load control, interruptible/curtailable programs, demand bidding, emergency demand response, capacity market, ancillary service market and critical time rebate. Among the DR techniques, price based methods are widely accepted 
because of ease of implementation. Real time pricing methods are more attractive because of its effectiveness compared to other methods.

Real time pricing for DR and home energy management system is the focus of many research works. RTP can be determined in different ways, considering the generating cost, network congestion, demand levels or a combination of these factors [5]. In [6] utility maximization of a smart grid is set as the objective of real time pricing strategy. Dynamic tariff can be predicted for DR programs using different methods like relevance vector, artificial neural networks or support vector machines [7], [8]. Many works on home energy management system (HEMS) to reduce energy expenditure according to RTP is available in the literature. One approch in HEMS is the optimal scheduling of appliances of a home for varying price signals [9]. The operational goals considered can be overall cost reduction, climatic comfort, user comfort or balanced load. Chen [10] an RTP based power scheduling algorithm is used. The final decision on the starting time of the home appliances in each home is decided based on the decision from the retailer or service provider and require huge computing capability at the retailer side. Bapat [11] 'jplugs' are used to derive usage pattern of appliances and will be mined for optimal solutions at varying prices. Time varying price along with appliance scheduling can reduce the energy expenditure for the consumers [12], [13].

The literature review revealed the importance of real time pricing with energy management solutions in the design of a demand response program. In smart homes, electrical appliances are connected with a proper communication mechanism to a control center in the house. The accumulated usage data of millions of consumers at the control centre will be of the size of big data. Analysis of this big data can reveal the diverse nature of the energy usage of consumers. The result of real time behaviour analysis can be used in the real time price design and can effectively alter the usage pattern for DR programs. But none of the work addressed the problem of building RTP based on the actual dynamic load profiles taken in the perspectives of both consumers and utilities. Segmentation of consumers based on energy usage pattern and real-time price design based on typical load profiles (TLPs) of consumers is an efficient method for retailers to ensure profit [14]. But there is uncertainty about achieving the estimated profit because of the elasticity of consumers against the price increase. For example, in the United States, long-term price elasticity by industries is 1.2 or greater, which is higher than often believed [15]. Hence, a more realistic optimization formulation for expected profit is needed and must address the elasticity of consumers [16]. To reduce the uncertainty of profit, price elasticity of consumers can be included in the RTP design. Also consider the large number of consumers and hence consumption data analysis method must be suitable to be implemented through stream computing and ensemble methods to support big data. At the same time, in load management activities, the involvement of distributor must be avoided or minimized to reduce computation burden for distributors and to protect consumers from privacy threats.

This paper presents a real time price (RTP) design considering real time load profile and price elasticity of consumers. The method is suitable for incorporating the behaviour of consumers from a big data environment and protecting the privacy of consumers. Home energy management system proposed here is capable to obtain optimum load scheduling strategy considering the consumer preferences without the intervention of distributors. Results clearly indicate that the solution is capable to reduce peak load of the system and energy bills in a DR program. This paper is organized as follows. Section 2 presents the comprehensive model of the DR system. Real time price design and home energy management are the two components of this system. Section 3 gives the results of the implementation and section 4 presents the conclusions.

\section{RESEARCH METHOD}

\subsection{Load profile based RTP design for DR programs}

In this section, a model for determining the real time price (RTP) that can be used by retailers are given. The target of the retailer is to set the real time price by considering the purchase price and real time response of the consumer. For this the Load Profile of different class of consumers is required. Towards this find the number of clusters among the consumers, from consumption history, based on an algorithm suitable for big data processing [17]. Then, determine the typical load profile (TLP) for each cluster relevant for the day and the retail price for each cluster based on price elasticity and the size of the cluster. In this step, stream computing technology can be used for data analysis and principles of ensemble clustering for clustering and TLP construction. Details of real time clustering for TLP construction using the ensemble method is given in [18]. This method is a 2-stage clustering algorithm, which can work well with big data to generate real time clustering of objects. In the first step, a set of cluster labels are created from the same/different view of the data with different/same algorithm/s. In second stage cluster labels are made by applying a consensus function over the previous set of cluster labels. In smart grid, the first stage can be used to create the clusters of each day using daily consumption data. Typical load profiles can be made in the second stage, which needs only cluster labels of a selected period (window). The retailer will announce the 
price for each cluster. Consumers will respond to real time prices either through automated energy management systems or manually reducing their loads. After announcing the price, receive the energy consumption data from each consumer and calculate the total energy consumption of the day. At the end of each day, reconstruct the typical load profile (TLP) by including current data and use this in next day price calculation.

The objective of real time pricing strategy is to determine the optimal price for different time slots considering the generation cost and demand of that time slot. Variation in prices for different groups of consumers is allowed based on their usage pattern. While varying prices, retailers cannot expect the calculated profit because of the random behaviour of consumers to variation in prices. This random behaviour can be best modelled by the introduction of price elasticity $(\beta \mathrm{k})$ of consumers in the profit function. The objective function to maximize the profit of the retailer is given in (1).

$$
P=\sum_{k=1}^{K} \sum_{c=1}^{N C(k)} \sum_{h=1}^{H} E_{k h}\left(1+\frac{\beta_{k}\left(R_{k h}-R_{h}\right)}{R_{h}}\right) R_{k h}-\sum_{k=1}^{K} \sum_{c=1}^{N C(k)} \sum_{h=1}^{H} E_{k h} R_{h}
$$

In (1), the term $\mathrm{P}$ represents the profit, and the first term represents the revenue generated by the retailer while selling electricity to consumers of different clusters according to their load profile. The second term gives the purchasing cost of energy from the wholesale market. Ekh denotes the load profile of cluster $k$ at hour h, where $k$ varies from 1 to $\mathrm{K}$ (the number of clusters), and $R k h$ indicates the selling price at hour $h$ to a cluster member $\mathrm{k}$ of $\mathrm{K}$. $\beta \mathrm{k}$ denotes the price elasticity of consumer in cluster $k$. As of price increases, consumption decreases and hence, price elasticity is usually negative and ranges from -0.01 to -0.25 [19]. $N C(k)$ denotes the number of members in cluster $\mathrm{k}$. $R h$ is the purchasing cost for energy incurred to the retailer. Constraint for the objective function is defined by (2). The constraint for profit is denoted in terms of profit percentage $(P P)$ of the (2) which can be decided by the distributor after considering the overall expenses and investments. If $E k h$ is the load profile at price value $R h$ then the expecting load by varying the price can be denoted by (3).

$$
\begin{aligned}
& \sum_{k-1}^{K} E_{k h} R_{k h} N C(k) \leq \sum_{k=1}^{K} E_{k h} R_{h} N C(k) * P P, \forall h \in[1-H] \\
& \mathrm{E}_{\text {khnew }}=E k h\left(1+\frac{\beta \mathrm{k}(\mathrm{Rkh}-\mathrm{Rh})}{R h}\right)
\end{aligned}
$$

\subsection{Design of an automated home energy management system}

Home energy management system aims to minimize the energy expenditure of a smart home by controlling the operations of various home appliances. For this purpose, an objective function is needed to be formulated to find the optimal operation schedule for various types appliances/loads such as to minimize the total cost. Based on the mode of working, different home appliances can be broadly classified into three: shiftable appliances, nonshiftable/critical loads and adjustable/curtailable loads [20], [21]. In some homes, renewable generation (eg.PV) facilities may be integrated, and the battery storage system can be used to store surplus energy and power, which can be consumed at high price hours. For each controllable load, the time slot during which they should operate is found by considering the operational constraints related to the controllable loads. Modelling of various types of appliances is given below.

\subsubsection{Load modelling}

Mathematical model of various types of loads and their constraints are specified in this section. Nonshiftable loads consume a fixed amount of energy at each hour during a working slot, and there is no flexibility to adjust the energy consumption in response to the price and hence no mathematical constraints are existing [22]. This leads to the possibility of some fixed load in each time slot irrespective of the rate of energy. Once started the operation of noninterruptible appliances will continue till the end of the job, while interruptible appliances can suspend its operation and can resume the job at low price hours. Noninterruptible loads represents shiftable, but not interruptible once it has begun. Non-interruptible loads will not suspend its operation, once it has started. While scheduling, we have to specify the number of continuous slots required by the appliance. Let Xij denote the on/off state of appliance $\mathrm{j}$ at time slot $\mathrm{i}$. pwj denote the rating of device $\mathrm{j}$ and $\mathrm{nt}$ indicate the number of time slots in a day. dpwj denote the power consumed by the appliance during a time slot. Let NIn be the number of non-interruptible devices in a home and ns be the number of time slots per hours. Let $\mathrm{Lj}$ denote the number of continuous time slots the device to be on between the specified starting and ending time $(\alpha \mathrm{j}$ : $\beta \mathrm{j})$. Let $\mathrm{Sj}$ denotes the scheduled starting time of an appliance. Then the appliance will be off during hours outside of the scheduling window. The equality constraints for non-interruptible load is specified in (4) and (5), and (6) gives the objective function. 


$$
\begin{aligned}
& \sum_{i=s j}^{s j+L j} X_{i j}=L j, s . t \alpha j \leq s j \leq \beta j-L j \\
& \mathrm{X}_{\mathrm{ij}}=0 ; \quad \forall i \notin\left[s_{j} . . s_{j}+L j\right] \\
& \operatorname{minf}_{N I}(X)=\sum_{i=1}^{n t} \operatorname{cost}_{i} *\left(\sum_{j=1}^{N I n} d p w_{j} * X_{i j}\right)
\end{aligned}
$$

For the case of interruptible devices, let In denote the number of interruptible devices in a home and $\mathrm{ns}$ be the number of time slots per hours. Let $\mathrm{Lj}$ indicate the number of time slots the device to be on between the specified starting and ending time $(\alpha \mathrm{j}: \beta \mathrm{j})$. No operation is required for hours outside the scheduling window. The equality constraints for the interruptible load is specified in (7) and (8), and (9) gives the objective function.

$$
\begin{aligned}
& \sum_{i=\alpha j}^{\beta j} X_{i j}=L j \\
& \mathrm{X}_{\mathrm{ij}}=0 ; \forall i \notin\left[\alpha_{j} . \beta_{j}\right] \\
& \operatorname{minf}_{I}(X)=\sum_{i=1}^{n t} \operatorname{cost}_{i} *\left(\sum_{j=1}^{I n} d p w_{j} * X_{i j}\right)
\end{aligned}
$$

For adjustable/curtailable loads fix a working window and specify the minimum and maximum acceptable consumption levels $\left(\mathrm{Cj}^{\mathrm{min}} ; \mathrm{Cj}^{\mathrm{max}}\right)$. For adjustable appliances, consumer may choose either comfort based scheduling or budget based scheduling. Hence two types of the optimization model are possible for adjustable appliances. If the objective is to minimize the expenditure, then consumer specifies a minimum level of comfort to bring the expenditure to the lowest possible value. This minimum comfort level can be ensured by imposing a constraint that within the scheduling window, the appliance should work in a minimum duration, i.e, $\mathrm{Lj}^{\mathrm{min}} \leq . \sum_{i=\alpha j}^{\beta j} X_{i j}$. The corresponding objective function can be specified as (10), where $\mathrm{Cn}$ is the number of adjustable appliances in a home.

$$
\begin{aligned}
& \operatorname{minf}_{C 1}(X)=\sum_{i=1}^{n t} \operatorname{cost}_{i} *\left(\sum_{j=1}^{C n} d p w_{j} * X_{i j}\right) S . T \mathrm{Cj}^{\min } \leq d p w_{j} \leq C j^{\max } \\
& \text { AND }{ }^{\min } \leq \sum_{i=\alpha j}^{\beta j} X_{i j} .
\end{aligned}
$$

If the objective is to maximize the life quality of consumers for a given budget, then the consumer will specify an expenditure limit for the given appliance as Expnj ${ }^{\max }$. Then the objective function can be modelled as given in (11).

$$
\begin{aligned}
& \operatorname{minf} 2(X)=\sum_{i=1}^{n t} \operatorname{cost}_{i} *\left(\sum_{j=1}^{C n} d p w_{j} * X_{i j}\right) \text { s.t } \sum_{i=1}^{n t} \operatorname{cost}_{i} *(d p w j * X i j) \leq \text { Expn }^{\text {max }} \\
& \text { and } C j^{\text {min }} \leq d p w_{j} \leq C j^{\text {max }}
\end{aligned}
$$

Even though, energy storage system come under the category of curtailable loads, objective function and constraints for ESS have to be formulated separately because there are two types of operation exist for this device; charging and discharging. In scheduling problem, separate vectors are needed to specify the charging and discharging cycle of ESS. If $\mathrm{Xj}$ denote the vector of charging schedule and $\mathrm{Xj}+1$ denote the vector of discharging schedule, then $X j . X j+1=0$. Also at each time slot, the charge of battery should be greater than the minimum required. DPWJ is the charging/discharging power of ESS in a fixed time slot. ESSij denotes the charge in the battery at time slot $i$ and it is specified in (12). If PV is integrated then the battery should be scheduled to be charged during day time only. If $\alpha j$ and $\beta j$ denotes the sunrise and sunset of the day, (13) denotes the required criteria. Another constraint for ESS is that the number of slots the battery charged should be equal to the number of discharge slots and is specified in (14).

$$
\begin{aligned}
& \text { ESSmin } \leq \mathrm{ESSi}-1 \mathrm{j}+(\mathrm{Xij}-\mathrm{Xij}+1) * \mathrm{dpwj} \leq \mathrm{ESSmax}, \forall i \in[1 . . n t] \\
& X i j=0, \forall i \notin[\alpha \mathrm{j} . . \beta \mathrm{j}] \\
& \sum_{i=1}^{n t} X i j=\sum_{i=1}^{n t} X_{i j+1}
\end{aligned}
$$


The objective function of ESS is given in (15). Here we aim to minimize the charging cost by appropriately scheduling charging and discharging to maintain a desired level of charge in the battery in desired cycles [23].

$$
\operatorname{minf} \operatorname{Ess}(X)=\sum_{i=1}^{n t}\left(\operatorname{cost}_{i} * d p w_{j} *\left(X_{i j}-X_{i j+1}\right)\right)
$$

\subsubsection{Objective function of HEMS}

Optimization problem to reduce energy expenditure in a smart home can be formulated as (16).

$$
\operatorname{minf} f_{o b j}(X), \text { w.r.t. } A_{e q} \cdot X=B_{e q} \text { and } A_{\text {ineq }} \cdot X=B_{\text {ineq }}
$$

where fobj(X) is the objective function, which is the total cost of operation for the day. Aeq denotes the permissible time slots for each appliance. The number of rows of Aeq is equal to the number of devices and the number of columns of Aeq $=$ na $*$ nt. For e.g. if we have 5 devices and 48 time slots/day, then the number of rows of Aeq $=5$ and the number of columns is 240. Set the cells $A[j ;(j-1) * 48]$ to $A[j ; j * 48]=$ $0 / 1$ to make the appliance $\mathrm{j}$ to be off/on during time slots 1 to $48 . X[(j-1) * 48]$ to $X[j * 48]$ denotes the schedule of device $\mathrm{j}$. Binary integer programming is used to solve the optimization problem formulated [24]. The total cost of energy traded with the grid is found out by summing up the cost of energy exchanged with the grid during individual time slots. Cost of energy exchanged with the grid during an individual time slot is found by multiplying the power exchanged with the grid by the cost of energy during the time slot and duration of a time slot. Our objective function can be formulated as,

$$
\operatorname{minf}_{o b j}(X)=\sum_{i=1}^{n t} \operatorname{cost}_{i} *\left(\sum_{j=1}^{n a} p w j * X_{i j}\right)
$$

where nt is the number of time slots, and na is the number of appliances and costi is the cost of energy at time slot $\mathrm{i}$. pwj is the power of appliance $\mathrm{j}$ and $\mathrm{Xij} 2 \mathrm{fO}=1 \mathrm{~g}$ which indicate the status of appliance $\mathrm{j}$ at time $\mathrm{i}$. Xij $=$ 0 if the device is off and 1 if the device is on. But our load consists of different kind of loads and each has different constraints and formulation. So our final objective function can be formulated as a combination of optimization of different models. There are two types of optimizations for adjustable loads. Hence the user can finally select either (18) or (19) based on their preference on adjustable loads.

$$
\begin{aligned}
& \operatorname{minf}_{o b j 1}(X)=\min \left(f_{N I}(X)+f_{I}(X)+f_{E S S}(X)+f_{C 1}(X)\right) \text { subject to constr. [(15), (6), (9), (11)] } \\
& \left.\left.\operatorname{minfobj} 2(X)=\min \left(f_{N I}(X)+f_{I}(X)+f_{E S S}(X)-f_{C 2}(X)\right) \text { subject to constr. [(15), ( } 6\right),(9),(11)\right]
\end{aligned}
$$

\section{RESULTS AND DISCUSSION}

Real time price is fixed from real time load profiles (RTLP) of consumers. We used consumption data from 200 residential consumers in half hour intervals collected from smart meters installed as part of the smart grid pilotproject in Mysore, India to construct the real time load profile [25]. There are 48 data points in a day for each consumer, as the meter data is reported in 30 minutes interval. As the initial step to construct RTLP, load values from the consumers are clustered using ensemble clustering. Ensemble clustering is a promising method to cluster real time big data for analysis. The optimum number of clusters resulted from the data is 3 . Cluster 1 contains $47.5 \%$ consumers with a monthly consumption of below 50 units. Cluster 2 contains $44.5 \%$ consumers with a monthly consumption between 50 to 250 units. Cluster 3 contains $8 \%$ consumers with a monthly consumption of between 250 to 325 units. The real time load profiles (RTLP) of clusters are given in Figure 1(a). Real time retail price is calculated from real time purchasing price by solving the profit maximization function given in (1). The maximum limit for the profit set for $10 \%$ of the purchasing cost and the objective function solved for different values of price elasticity $(\beta)$. Energy profile of different clusters is given in Figure 1(a) and price profile of different clusters with varying $\beta$ is shown in Figure 1(b). From the graph, it is clear that as elasticity decreases price is increasing. In an environment with clusters having different elasticity, price will be high for clusters with low elasticity. Comparison of Figure 1(b) and Figure 1(a) reveals that prices are according to the energy profiles of different clusters. Cluster 2 has the highest energy usage, and hence the maximum price is assigned.

Home energy management is done using real time price announced by the distributor. Amount of monthly house hold energy consumption depends on the appliance penetration in each home. Energy is consumed by appliances like lights $(21 \%)$, fans $(16 \%)$, refrigerator $(11 \%)$, TV (11\%), air coolers $(1 \%)$, AC 
$(16 \%)$, water heater $(12 \%)$ and others $(13 \%)$. Based on this data and the load profile obtained from the clustering algorithms, we modelled three types of homes. Cluster one is modelled by a household consuming less than 50 units/month consumption (say Type-I). In such houses, we considered only non-schedulable loads. That type of homes assumed to have zero price elasticity. Cluster of type 2 represents houses with an average consumption of less than 250 units of electricity per month (say Type-II) and have schedulable loads along with the loads present in cluster 1 houses. The third cluster represents houses with a usage of less than 325 units per month (say Type-III), which consists of high energy consuming loads like AC and water pumps. Along with appliances included in cluster 2 houses. Table 1 give the schedule of loads considered in the three types of houses. We have done optimized scheduling of appliances for real time prices without considering load profile, based on load profile and flat price and calculated the average energy expenditure for three types of houses and the expected profit for the retailer based on load profile and the real profit after scheduling of the appliances.

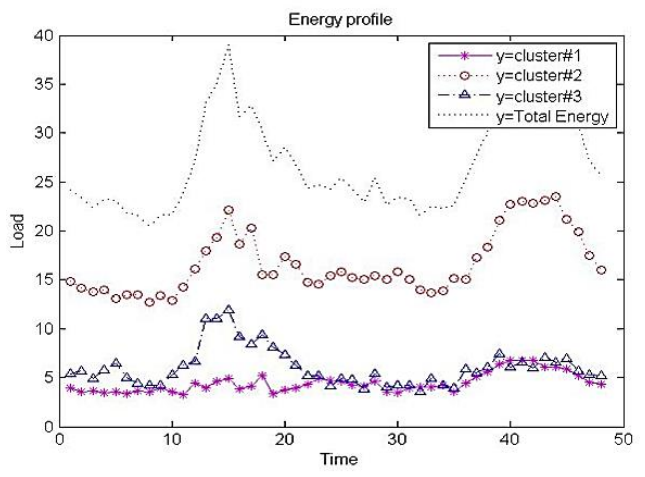

(a)

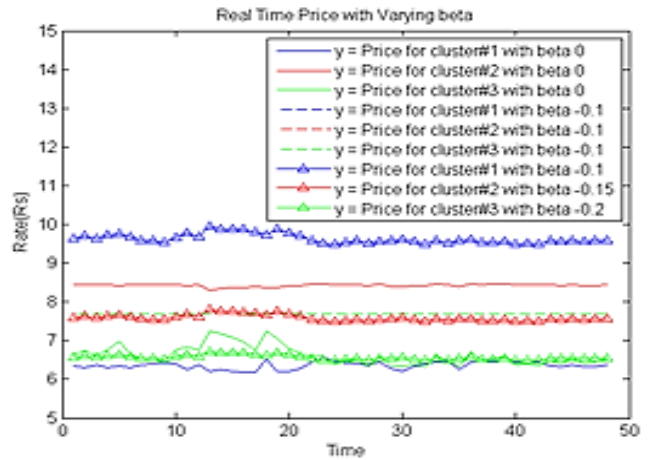

(b)

Figure 1. These figures are; (a) cluster based load profile of consumers, (b) RTP for different values of $\beta$

Table 1. Loads installed in three type of houses

\begin{tabular}{|c|c|c|c|c|}
\hline Load & Rated Power & Working Time & Working Duration & Installed in Homes \\
\hline Lighting load (bulb) & $60 \mathrm{~W}$ & $5 \mathrm{AM}$ to $9 \mathrm{AM}$ & $4 \mathrm{hrs}$ & Type I, II, III \\
\hline Lighting load (bulb) & $60 \mathrm{~W}$ & $5 \mathrm{PM}$ to $9 \mathrm{PM}$ & $4 \mathrm{hrs}$ & Type I, II, III \\
\hline Lighting load (CFL) & 20W & $5 \mathrm{AM}$ to $9 \mathrm{AM}$ & $4 \mathrm{hrs}$ & Type I, II, III \\
\hline Lighting load (CFL) & $20 \mathrm{~W}$ & $5 \mathrm{PM}$ to $10 \mathrm{PM}$ & $5 \mathrm{hrs}$ & Type I, II, III \\
\hline Lighting load (tube) & 40W & $7 \mathrm{AM}$ to $9 \mathrm{AM}$ & $2 \mathrm{hrs}$ & Type I, II, III \\
\hline Lighting load (tube) & 40W & $9 \mathrm{AM}$ to $12 \mathrm{PM}$ & $12 \mathrm{hrs}$ & Type I, II, III \\
\hline Lighting load (tube) & 40W & $6 \mathrm{AM}$ to $8 \mathrm{AM}$ & $2 \mathrm{hrs}$ & Type I, II, III \\
\hline Ceiling Fan & $80 \mathrm{~W}$ & $7 \mathrm{PM}$ to $10 \mathrm{PM}$ and $1 \mathrm{AM}$ to $6 \mathrm{AM}$ & $5 \mathrm{hrs}$ & Type I, II, III \\
\hline Ceiling Fan & $80 \mathrm{~W}$ & $7 \mathrm{AM}$ to $9 \mathrm{AM}$ & $2 \mathrm{hrs}$ & Type I, II, III \\
\hline Battery Charger & $7 \mathrm{~W}$ & $6 \mathrm{AM}$ to $8 \mathrm{AM}$ & $2 \mathrm{hr}$ & Type I, II, III \\
\hline Telivision & $200 \mathrm{~W}$ & $5 \mathrm{PM}$ to $9 \mathrm{PM}$ & $2 \mathrm{hrs}$ & Type II, III \\
\hline Laptop Computer & $50 \mathrm{~W}$ & $7 \mathrm{PM}$ to $11 \mathrm{PM}$ & $2 \mathrm{hrs}$ & Type II, III \\
\hline Fridge & 350W & $1 \mathrm{AM}$ to $12 \mathrm{AM}$ & $15 \mathrm{hr}$ & Type II, III \\
\hline Iron Box & 500W & $7 \mathrm{AM}$ to $9 \mathrm{AM}$ and $5 \mathrm{PM}$ to $8 \mathrm{PM}$ & $1 \mathrm{hr}$ & Type II, III \\
\hline Washing Machine & $450 \mathrm{~W}$ & $12 \mathrm{AM}$ to $12 \mathrm{PM}$ & $1.5 \mathrm{hr}$ & Type II, III \\
\hline Pump Motor & $750 \mathrm{~W}$ & $8 \mathrm{PM}$ to $11 \mathrm{PM}$ & $0.5 \mathrm{hrs}$ & Type III \\
\hline Air Conditioner & $1000 \mathrm{~W}$ & $10 \mathrm{PM}$ to $12 \mathrm{AM}$ and $1 \mathrm{AM}$ to $6 \mathrm{AM}$ & $4 \mathrm{hrs}$ & Type III \\
\hline Microwave Oven & $850 \mathrm{~W}$ & $7 \mathrm{PM}$ to $8 \mathrm{PM}$ & $0.5 \mathrm{hr}$ & Type III \\
\hline Desktop Computer & 270W & $4 \mathrm{PM}$ to $10 \mathrm{PM}$ & $3 \mathrm{hr}$ & Type III \\
\hline Toaster & 900W & $7 \mathrm{AM}$ to $8 \mathrm{AM}$ & $0.5 \mathrm{hr}$ & Type III \\
\hline
\end{tabular}

After running the scheduling algorithm, Figure 2(a) shows the schedule of loads in a type-I home based on the operating slots given in Table 1 and Figure 2(b) shows the energy price versus total load in a house belonging to type-I under RTP. Similarly, Figure 3(a) shows the schedule of loads and Figure 3(b) shows the energy price versus total load in a type-II house after optimized scheduling of appliances according to Table 1. Figure 4(a) shows the optimized schedule of loads based on Table 1 and Figure 4(b) shows the energy price versus total load in a type-III house under RTP. From Figure 3(b) it is clear that when the price is above the average of the day (Rs. $4 / \mathrm{KWh}$ ), the total load of the house made the minimum to reduce the expenditure. This reduction in load shows the good performance of the optimization algorithm. Table 2 
shows the energy expenditure per day in the three types of houses for RTP and flat pricing scheme. From Table 2 it is clear that expenditure of homes with shiftable/adjustable loads (Type-II, Type-III) is less in RTP based tariff scheme. This shows the positive effect of RTP on DR programs.

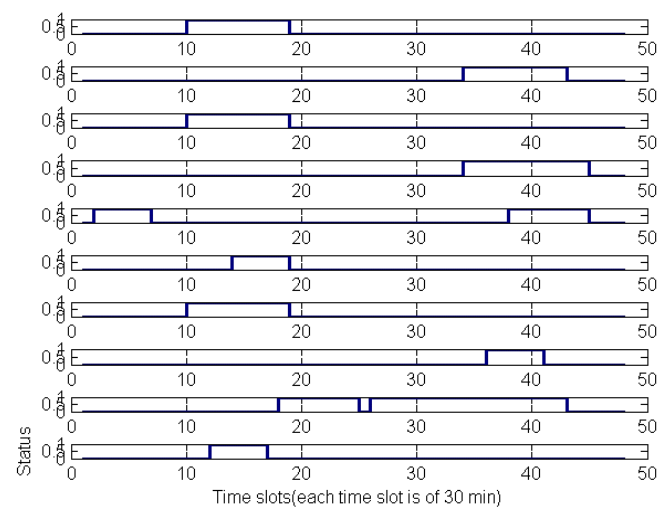

(a)
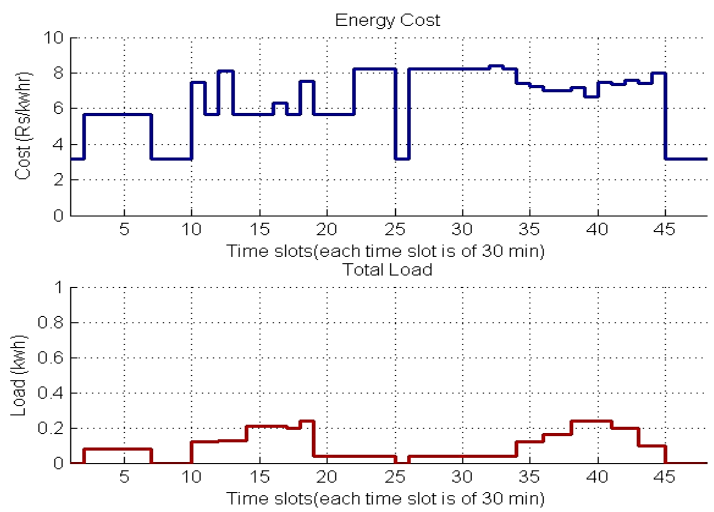

(b)

Figure 2. These figures are; (a) appliance schedule of type-I homes, (b) cost vs total load of type -1 homes

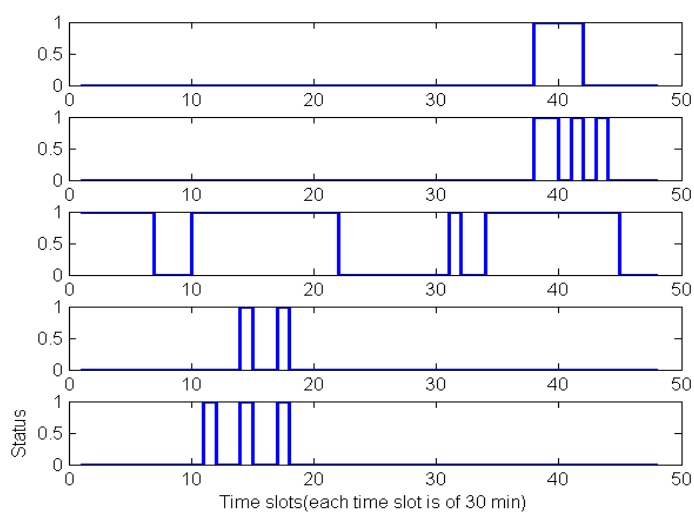

(a)
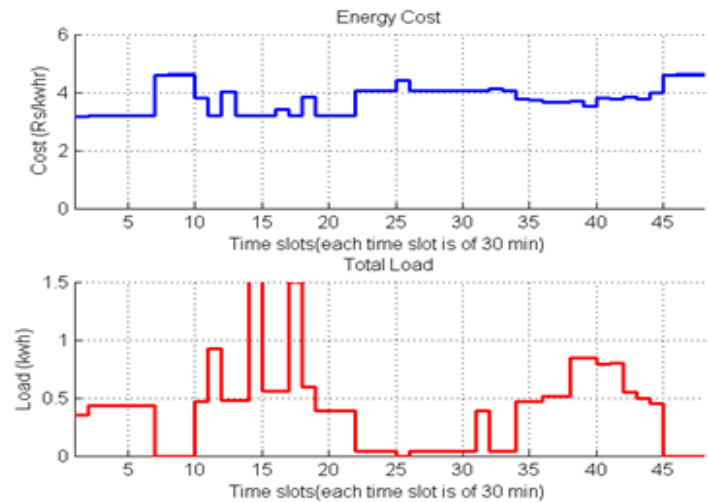

(b)

Figure 3. These figures are; (a) schedule of major appliancesof type-II homes,

(b) cost vs total load oftype-II homes

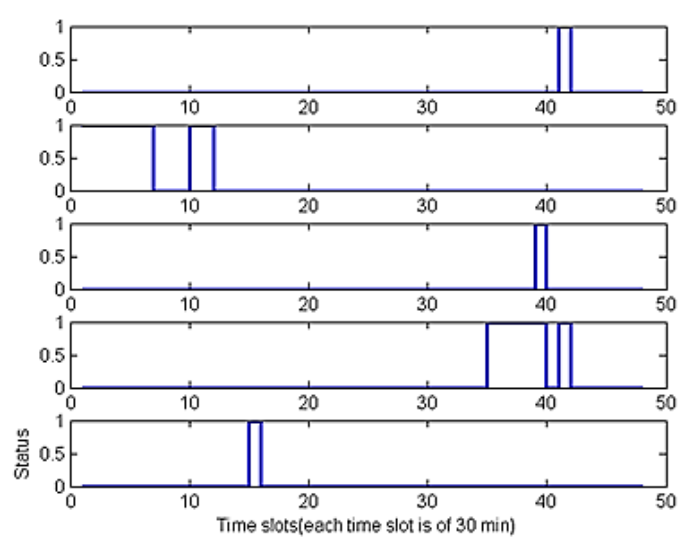

(a)
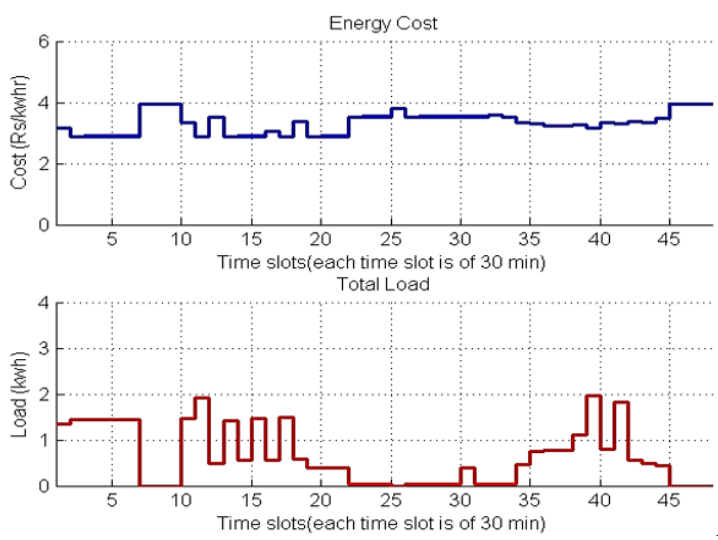

(b)

Figure 4. These figures are; (a) Schedule of major appliances of type-III homes,

(b) cost vs total load of type-III homes 
Table 2. Energy expenditure of houses per day (in Rs.)

\begin{tabular}{cccccc}
\hline $\begin{array}{c}\text { Type of } \\
\text { House }\end{array}$ & $\begin{array}{c}\text { Flat } \\
\text { price(Rs) }\end{array}$ & $\begin{array}{c}\text { RTP( without } \\
\text { considering } \\
\text { Load Profile, } \\
\beta=0)\end{array}$ & $\begin{array}{c}\text { RTP(Considering } \\
\text { Load Profile, } \beta=0)\end{array}$ & $\begin{array}{c}\text { RTP(Considering } \\
\text { Load Profile, } \beta \\
=-0.1)\end{array}$ & $\begin{array}{c}\text { RTP(Considering } \\
\text { Load Profile, } \beta=- \\
0.2)\end{array}$ \\
\hline $50 \mathrm{KW}$ & 10.078 & 10.7317 & 10.7312 & 10.7317 & $\begin{array}{c}\text { RTP(Considering } \\
\text { Load Profile, } \beta=- \\
0.1,-0.2,-0.3)\end{array}$ \\
$250 \mathrm{KW}$ & 41.8367 & 40.5805 & 40.5800 & 40.5815 & 10.7317 \\
$325 \mathrm{KW}$ & 69.6285 & 66.5356 & 66.5343 & 66.5274 & 60.5801 \\
\hline
\end{tabular}

\subsection{Impact of RTP on DR program}

The profit for the retailer calculated against real time pricing without considering load profile, considering load profile and flat pricing in different cases (by the varying beta value for each clusters). Flat price is fixed as the $10 \%$ increased value of average purchase price. In another case RTP is fixed without considering the load profile and elasticity of clusters. Here, same price is fixed for each slot among clusters, which is $10 \%$ increased value of real time purchase price. In other cases varying selling price is fixed for each cluster depending on the load profile and elasticity of clusters using our formulation mentioned in (1). Table 3 shows the minimum profit ensured by the distributor based on flat pricing and real time pricing for the above described cases. One significant result is that, daily expenditure for consumers are reduced once prices are offered based on their load profile. A minimum profit is ensured in all cases with varying $\beta$. Another significant result is that the peak load of the system is reduced, comparing to flat pricing. Figure 5 shows the total load of the system when RTP implemented against flat pricing. In all cases with suitable beta values (price elasticity), RTP scheme has a lower peak compared to a flat pricing scheme.

Table 3 Profit gained by retailer (in Rs.)

\begin{tabular}{ccccc}
\hline Profit & RTP (without & RTP (Considering & RTP (Considering & RTP (Considering \\
& considering TLP, $\beta$ & Load Profile, $\beta=-$ & Load Profile, $\beta=-$ & Load Profile, $\beta=-$ \\
& $=0$ ) & $0.1)$ & $0.2)$ & $0.1,-0.2,-0.3)$ \\
\hline Expected Profit & 556.68 & 495.44 & 434.21 & 430.58 \\
Profit After & 128.8488 & 128.9194 & 128.8524 & 128.8429 \\
Scheduling & & & & 213.90 \\
\end{tabular}

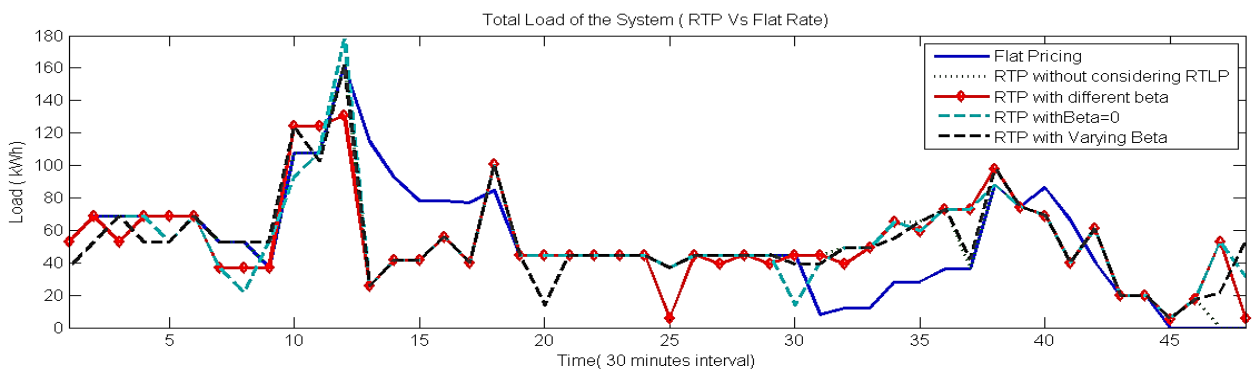

Figure 5. Total load of the system under RTP

\section{CONCLUSION}

A practical solution for DR beneficial for both consumers and utilities is a major issue in a smart grid. In this paper, we proposed a comprehensive DR model based on real time pricing (RTP) for the big data environment of the smart grid and analysed the impact of RTP on DR programs. A real time load profile (RTLP) based RTP for DR programs was designed with a real time clustering algorithm suitable for big data. Real consumption data collected from a smart grid pilot project in India was used in the simulations. RTLP is generated from real time metering data by the ensemble clustering method. Simulation results show that optimal RTP strategy along with optimal scheduling of home appliances is suitable for the demand response program to reduce the peak load of the system and energy expenditure of houses while ensuring a minimum profit for the retailer. In future the integration of renewable energy sources in smart buildings to reduce the dependence on grid power is to be considered. Work can be extended to interface IoT and big data analytics for monitoring and data visualization. Also objective function can be formulated to minimize the inconvenience for the consumer. Interfacing of this scheduling algorithm with proper communication method in advanced metering infrastructure (AMI) can leverage the system to commercial level. 


\section{REFERENCES}

[1] V. M. Balijepalli, V. Pradhan, S. Khaparde, and R. Shereef, "Review of demand response under smart grid paradigm," ISGT2011-India, Kollam, India, 2011, pp. 236-243, doi: 10.1109/ISET-India.2011.6145388.

[2] D. Mahmood, N. Javaid, N. Alrajeh, Z. A. Khan, U. Qasim, I. Ahmed et al., "Realistic scheduling mechanism for smart homes," Energies, vol. 9, no. 3, 2016, Art. no. 202, doi: 10.3390/en9030202.

[3] Q. Qdr, "Benefits of demand response in electricity markets and recommendations for achieving them," US Dept. Energy, Washington, DC, USA, Tech. Rep, 2006.

[4] R. Moreno, J. Obando, and G. Gonzalez, "An integrated opf dispatching model with wind power and demand response for day-ahead markets," International Journal of Electrical and Computer Engineering (IJECE), vol. 9, no. 4, pp. 2794-2802, 2019, doi: 10.11591/ijece.v9i4.pp2794-2802.

[5] Y. Gu, J. Xie, X. Chen, K. Yu, Z. Chen, and Z. Li, "Dynamic tariff method for congestion management in distribution networks," 2017 IEEE Conference on Energy Internet and Energy System Integration (EI2), Beijing, China, 2017, pp. 1-6, doi: 10.1109/EI2.2017.8245296.

[6] P. Samadi, A.-H. Mohsenian-Rad, R. Schober, V. W. Wong, and J. Jatskevich, "Optimal real-time pricing algorithm based on utility maximization for smart grid," 2010 First IEEE International Conference on Smart Grid Communications, Gaithersburg, MD, USA, 2010, pp. 415-420, doi: 10.1109/SMARTGRID.2010.5622077.

[7] M. Alamaniotis, D. Bargiotas, N. G. Bourbakis, and L. H. Tsoukalas, "Genetic optimal regression of relevance vector machines for electricity pricing signal forecasting in smart grids," IEEE Transactions on Smart Grid, vol. 6, no. 6, pp. 2997-3005, 2015, doi: 10.1109/TSG.2015.2421900

[8] C. Monteiro, I. J. R.-Rosado, L. A. F.-Jimenez, and P. Conde, "Short-term price forecasting models based on artificial neural networks for intraday sessions in the iberian electricity market," Energies, vol. 9, no. 9, pp. 721-744, 2016, doi: 10.3390/en9090721.

[9] A. Agnetis, G. Dellino, P. Detti, G. Innocenti, G. De Pascale, and A. Vicino, "Appliance operation scheduling for electricity consumption optimization," 2011 50th IEEE Conference on Decision and Control and European Control Conference, Orlando, FL, USA, 2011, pp. 5899-5904, doi: 10.1109/CDC.2011.6160450.

[10] C. Chen, S. Kishore, and L. V. Snyder, "An innovative rtp-based residential power scheduling scheme for smart grids," 2011 IEEE International Conference on Acoustics, Speech and Signal Processing (ICASSP), Prague, Czech Republic, 2011, pp. 5956-5959, doi: 10.1109/ICASSP.2011.5947718.

[11] T. Bapat, N. Sengupta, S. K. Ghai, V. Arya, Y. B. Shrinivasan, and D. Seetharam, "User-sensitive scheduling of home appliances," Proceedings of the 2nd ACM SIGCOMM workshop on Green networking, 2011, pp. 43-48, doi: 10.1145/2018536.2018546.

[12] X. Chen, T. Wei, and S. Hu, "Uncertainty-aware household appliance scheduling considering dynamic electricity pricing in smart home," IEEE Transactions on Smart Grid, vol. 4, no. 2, pp. 932-941, 2013, doi: 10.1109/TSG.2012.2226065.

[13] T. Logenthiran, D. Srinivasan, and T. Z. Shun, "Demand side management in smart grid using heuristic optimization," IEEE Transactions on Smart Grid, vol. 3, no. 3, pp. 1244-1252, 2012, doi: 10.1109/TSG.2012.2195686.

[14] N. M.-Kohan, M. P. Moghaddam, M. S.-El-Eslami, and E. Shayesteh, "A three-stage strategy for optimal price offering by a retailer based on clustering techniques," International Journal of Electrical Power and Energy Systems (IJPEDS), vol. 32, no. 10, pp. 1135-1142, 2010, doi: 10.1016/j.ijepes.2010.06.011.

[15] P. J. Burke and A. Abayasekara, "The price elasticity of electricity demand in the United States: A three dimensional analysis,” SSRN Electronic Journal, no. 50, pp. 1-34, 2017, doi: 10.2139/ssrn.3016911.

[16] M. Aliakbari, P. Maghouli, and H. A. Aalami, "Reliability constrained unit commitment considering the effect of $\mathrm{dg}$ and dr program," International Journal of Electrical and Computer Engineering (IJECE), vol. 8, no. 4, pp. 1985-1996, 2018, doi: 10.11591/ijece.v8i4.pp1985-1996.

[17] S. Joseph and E. A. Jasmin, "Stream computing framework for outage detection in smart grid," 2015 International Conference on Power, Instrumentation, Control and Computing (PICC), Thrissur, India, 2015, pp. 1-5, doi: 10.1109/PICC.2015.7455744.

[18] S. Joseph and E. Jasmin, "Real-time retail price determination in smart grid from real-time load profiles," International Transactions on Electrical Energy Systems, vol. 28, no. 10, 2018, Art. No. e2509, doi: 10.1002/etep.2509.

[19] F. C. Schweppe, M. C. Caramanis, R. D. Tabors, and R. E. Bohn, "Spot pricing of electricity," Springer Science and Business Media, 2013

[20] Y. Zhang, P. Zeng, S. Li, C. Zang, and H. Li, "A novel multiobjective optimization algorithm for home energy management system in smart grid," Mathematical Problems in Engineering, vol. 2015, 2015, doi: 10.1155/2015/807527.

[21] T. Remani, E. Jasmin, and T. I. Ahamed, "Residential load scheduling with renewable generation in the smart grid: A reinforcement learning approach," IEEE Systems Journal, vol. 13, no. 3, pp. 3283-3294, 2019, doi: 10.1109/JSYST.2018.2855689.

[22] F. -L. Meng and X. -J. Zeng, "An optimal real-time pricing for demand-side management: A stackelberg game and genetic algorithm approach," 2014 International Joint Conference on Neural Networks (IJCNN), Beijing, China, 2014, pp. 1703-1710, doi: 10.1109/IJCNN.2014.6889608.

[23] R. Hemmati and H. Saboori, "Short-term bulk energy storage system scheduling for load leveling in unit commitment: modeling, optimization, and sensitivity analysis," Journal of advanced research, vol. 7, no. 3, pp. 360-372, 2016, doi: 10.1016/j.jare.2016.02.002.

[24] G. Carpinelli, A. Bracale, and P. Caramia, "The great project: Integer linear programming-based day-ahead optimal scheduling of a dc microgrid," 2013 12th International Conference on Environment and Electrical Engineering, Wroclaw, Poland, 2013, pp. 573-578, doi: 10.1109/EEEIC.2013.6549581. 
[25] M. F. Khan, A. Jain, V. Arunachalam, and A. Paventhan, "Roadmap for smart metering deployment for indian smart grid," 2014 IEEE PES General Meeting Conference and Exposition, National Harbor, MD, USA, 2014, pp. 1-5, doi: 10.1109/PESGM.2014.6939919.

\section{BIOGRAPHIES OF AUTHORS}

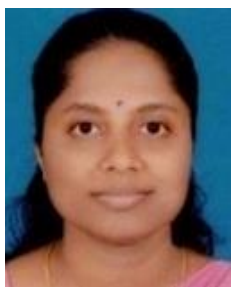

Shibily Joseph working as Associate Professor in Computer Science and Engineering Department and doing research at Electrical Engineering department of Government Engineering College, Thrissur, Kerala. She obtained her Bachelors Degree in Computer Science and Engineering from University of Calicut. She received her Masters degree in Computer Science and Engineering from National Institute of Technology Calicut, Kerala, India. Research Interest include Demand Response Programs and Smart Grid and published several research papers.

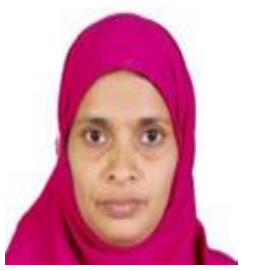

E. A. Jasmin is Associate Professor in Department of Electrical Engineering, Govt. Engineering College, Idukki, Kerala, India. She obtained her Bachelors degree in Electrical Engineering from Kerala University. She received her Masters degree in Computer Science and Engineering and $\mathrm{Ph} . D$. from Cochin University of Science and Technology, Kochi, Kerala, India. Her research interest include Smart Grid, Communications Systems and Power System Optimization. 